(6) OPEN ACCESS

- An online supplementary video and file are published online. To view this file please visit the journal online (http:// dx.doi.org/10.1136/bcr-2014203641)

Department of Rheumatology, Thomas Jefferson University, Philadelphia, Pennsylvania, USA

\section{Correspondence to}

Dr Michele Meltzler, michele.meltzer@jefferson.edu

To cite: Meltzler M. $B M$ Case Rep Published online: [please include Day Month Year] doi:10.1136/bcr-2014203641

\title{
Diagnosis and treatment of gout
}

\section{Michele Meltzler}

Gout is an ancient disease that has caused pain and suffering over many centuries. The tragedy is that today we have excellent medication for the prevention of chronic gout, yet many people continue to be plagued by gout attacks and develop chronic arthritis. The incidence of gout is increasing worldwide. This is related to ageing and lifestyle changes. Gout is increased in people with the metabolic syndrome, obesity, use of diuretics and intake of beer and sugared drinks.

This video and associated Powerpoint presentations should help anyone who manages patients with gout to understand how to elicit a good history, examine them and generate a differential diagnosis; the emphasis is to understand the causes of gout and take a proactive role (see online supplementary video and file). The good news is that gout can improve with lifestyle changes, and medication is relatively inexpensive.

I chose not to include pegloticase and rilonacept in the videos. Pegloticase is a recombinant uricase which catalyses the oxidation of uric acid to allantoin. Allantoin is much more soluble than uric acid. Pegloticase must be given intravenously; anaphylactic reactions have been caused by it and it is very expensive. But the reason I did not include pegloticase is its use represents a failure to properly diagnose and treat gout. If patients and medical professionals understand the diagnosis and treatment of gout, we would rarely see tophaceous gout and the need for pegloticase would be limited.

Rilonacept is an interleukin 1 inhibitor to be used to prevent flares of gout when initiating therapy with a hypouricaemic agent. The studies to establish efficacy were carried out on patients with a history of gout initiating therapy with allopurinol. The patients were started on allopurinol $300 \mathrm{mg}$ daily and then the dose was titrated upward until target level of serum uric acid was achieved. Patients were divided into two groups; one took rilonacept and the other was not allowed to take medications, such as colchicine or nonsteroidal anti-inflammatory drugs (NSAIDs), which could possibly prevent attacks of gout. The two groups were compared and there were fewer attacks of gout in the group taking rilonacept. The American College of Rheumatology suggested, in 2012, in their guidelines for the treatment of gout that the initial dose of allopurinol should be $100 \mathrm{mg}$ and the dose titrated every 2-5 weeks until target serum uric acid is achieved. The rationale is that by performing the slow titration of allopurinol, there would be fewer attacks of gout. The point is we do not know if this slow titration of allopurinol, with or without NSAIDs or colchicine, is less likely to cause flares of gout as compared with the use of rilonacept. However, rilonacept is a biological agent and is expensive.

\section{Competing interests None.}

Patient consent Obtained.

Provenance and peer review Not commissioned; externally peer reviewed.

Open Access This is an Open Access article distributed in accordance with the Creative Commons Attribution Non Commercial (CC BY-NC 3.0) license, which permits others to distribute, remix, adapt, build upon this work non-commercially, and license their derivative works on different terms, provided the original work is properly cited and the use is non-commercial. See: http://creativecommons.org/licenses/by-nc/3.0/ 